\title{
THE IMPACT OF ORGANISATIONAL CULTURE ON LEADERSHIP EFFECTIVENESS AND PERFORMANCE
}

\author{
Daniel METZ ${ }^{a *}$, Liviu ILIES $^{b}$, Maria METZ $^{c}$ \\ a , b, c Babes-Bolyai University, Romania
}

\begin{abstract}
Even though leadership is seen as an important instrument in promoting and consolidating organisational culture in business companies, organisational culture itself plays a significant role in ensuring the effectiveness of leadership and improving organisational performance. In the attempt to identify priority issues/goals for company leaders and leadership, another frequently encountered topic in specialised literature is the impact of organisational culture on the effectiveness of leadership and performance in large companies. The main variables under analysis concern the following aspects: orientation towards team work, core values, facilitation of change, strategic orientation / strategic direction and leadership effectiveness. Considering that the effectiveness of leadership depends on organisational culture, the present study integrates organisational culture and leadership in one single research model in order to examine the effects of their interaction, with an impact on leadership effectiveness as a prerequisite for ensuring the high performance of the company under analysis. The results obtained support the fact that organisational culture is a good predictor of leadership effectiveness and the improvement of organisational performance.
\end{abstract}

KEYWORDS: core values, effectiveness, leadership, organizational culture, strategic direction.

\section{INTRODUCTION}

Organisational culture, which stems from organisational behaviour theories, is seen as a collection of common hypotheses, values and beliefs reflected in organisational practices and goals. It determines the manner in which an organisation's leaders and other members adequately and effectively perceive, grasp and react to the changes in the internal and external environment. (Schein, 2009; Ogbonna and Harris, 2000; O’Reilly III et al., 2014).

In the last few years, organisational culture has been analysed in many studies, in different contexts, and identified as a critical factor that guides the elaboration, implementation and operationalisation of organisational strategies and policies, a field in which an organisation's leadership holds significant responsibilities (Ashkanasy and Dorris, 2018; Bass \& Avolio, 1993). Furthermore, E. Schein (2010) stresses the fact that leadership is seen as an important instrument in promoting and consolidating an adequate and strong organisational culture, yet organisational culture itself plays a significant role in ensuring the effectiveness of leadership as an important factor in the continuous improvement of performance. In the attempt to identify priority issues/goals for company leadership, another frequently encountered topic in specialised literature is the impact of organisational culture on leadership effectiveness in large companies.

\footnotetext{
*Corresponding author. E-mail address: daniel.metz@econ.ubbcluj.ro
} 
Schein stresses the fact that organisational culture is created, elaborated and developed by leaders. At the same time, it has the role of providing structure and stabilising it, as well as that of influencing the effectiveness of an organisation's leadership, while the ability to understand and manage organisational culture is considered to be a premise for leadership effectiveness (Schein, 2010; Wilderom \& van den Berg, 2000).

In the opinion of many specialists, which is shared by the authors, this study cannot speak of promoting and consolidating a strong, adequate culture capable of ensuring leadership effectiveness without having a profound understanding of the elements which define corporate culture.

Leadership and organisational culture influence each other, in the sense that leaders ensure the process of creation, promotion and consolidation of organisational culture, while, on the other hand, an adequate and functional organisational culture determines the effectiveness of leadership. In this context, organisational culture is created, elaborated, developed and manipulated by leaders in such a way that, in successful organisations, organisational culture is a source of stability and constraints and provides structure and meaning to the members of the organisations, thus determining the effectiveness of leadership. Nevertheless, a widely accepted view in the literature underlines the fact that organisational culture reflects the values, behaviour and actions of an organisation's leaders while influencing the strategy, structure, procedures and manners of interaction between group members (Schein, 2010; Schein, 2017; O’Reilly III et al., 2014).

\section{LITERATURE REVIEW}

\subsection{Organisational culture and leadership}

The specialised literature dedicated to organisational culture often refers to the role of leadership in creating and consolidating a strong organisational culture (Schein, 1992; Schein, 2010). Leadership is considered to be the ability to understand and manage organisational culture as a factor which determines its effectiveness. It indicates the manner in which the members of an organisation should behave and provides a clear direction meant to enable it to fulfil its vision and mission in order to attain its declared goals (Howell and Avolio, 1993; Schneider et al., 2013).

In spite of all the explicit or implicit assertions as to the relationship between organisational culture and leadership, which are found in abundance in the literature, few studies have researched the relationship between the two concepts, namely the impact of such a relationship on organisational effectiveness as an indicator for measuring performance.

Many studies start from the premise that corporate culture is part of the organisational context it occurs in and a driver for leadership, while other theorists and practitioners include organisational culture in leadership effectiveness enhancement projects, believing that a system of common values shared by the members of an organisation contributes to a good understanding of the context in which the company operates, thus making it easier to ensure leadership effectiveness, which is construed as a process of influencing employees in order to attain certain common goals (Schein, 1992; Parry and Proctor-Thomson, 2002; Schein, 2010; Schein, 2017; Ogbonna and Harris, 2000; Al-Tit, 2017).

One of the ways to examine the relationship between organisational culture and leadership consists in determining the impact which the features of organisational culture according to the Denison model have on leadership effectiveness by conceptualising organisational culture as an integral part of an organisation which shapes the behaviour of its leaders and other members (e.g.: Bass and Avolio, 1993; Ogbonna and Harris, 2000).

Primary mechanisms as instruments via which an organisation's leaders teach its members how to think, feel and act in ordinary or crisis situations, how to grant rewards and promotions, and how to select employees and allocate financial resources, together with secondary mechanisms consisting of organisational structure and design, systems and procedures, and organisation facilities, which consolidate organisational culture, help leaders convey and share common values with the other 
members of the organisation and adapt to the business environment in which they operate in order to ensure the organisation's success (Schein, 2010; Schneider et al., 2013).

Studies which have examined the relationship between leadership effectiveness and a strong organisational culture constantly focus on common core values and on orientation towards employees, clients, innovation, and results. Furthermore, effective leadership constantly stresses the following behaviours: taking an interest in employees, communicating and sharing one's vision, focusing on building relationships, monitoring operations and taking risks (Howell and Avolio, 1993; Tsui et al., 2006; Schneider et al., 2013).

Leadership comprises all the influence processes which affect the organisational behaviour of subordinates, the choice of goals for individual employees, teams or the organisation, the manner of organising work activities in order to reach goals, the motivation of subordinates in attaining goals, the orientation towards team work, and the maintaining of balance between cooperation and competition. The leaders of the organisation need to constantly evaluate their styles and perceptions of the leadership process and understand cultural differences, individual and team motivations, interpersonal abilities, creativity levels, the capacity to manage change, communication styles, the capacity to listen, decision-making abilities and personal ethics.

A leader needs to successfully build and motivate the teams within the organisation in order to fulfil its goals, which requires flexibility and the capacity to find creative and effective solutions while taking into account the fact that organisational change demands a proactive, future-oriented approach.

Considering that the effectiveness of leadership depends on organisational culture, the present study integrates organisational culture and leadership in one single research model in order to examine the effects of their interaction, with an impact on leadership effectiveness as a prerequisite for ensuring the high performance of the company under analysis.

Only an organisational culture based on strong strategic orientation, team work and flexibility, one that is founded on a system of common values shared by company members, can successfully focus on growth, creativity, innovation and a sense of belonging (Quinn and Rohrbaugh, 1983).

\section{RESEARCH METHODOLOGY}

The present study aims to present a series of results and conclusions obtained through research seeking to develop a model for the assessment and analysis of the organisational culture and leadership effectiveness of a multinational company, along with the relations of mutual conditioning between them.

The results of the study are based on methods of quantitative data analysis which use the questionnaire as their instrument, as well as on direct observation with the aim of assessing the features of organisational culture and the best leadership practices found in a multinational company, according to the perception of the questionnaire respondents.

The questionnaire is made up of adequate items, the object of which are the features of the organisational culture under analysis, namely: orientation towards team work, core values, facilitation of change and strategic orientation/direction. It also includes primary items/variables regarding the practices which ensure leadership effectiveness. The variables under analysis were measured using a Likert scale from 1 to 5 ( 1 - complete disagreement; 5 - complete agreement).

The research was based on a sample of 139 employees (managers and non-management employees), one that is representative of the company under analysis, given the structure of the group of respondents. The validated questionnaires were processed and analysed using the STATA 16 software.

The construct of the model for the measurement and analysis of organisational culture and leadership effectiveness comprises the following variables:

- Orientation towards team work (TEAM) 
- Core values (VAL)

- Facilitation of change (FACIL)

- Strategic orientation / strategic direction (ORT)

- Effectiveness of leadership (ELD)

\section{RESULTS}

\subsection{Analysis of leadership effectiveness}

In order to analyse the effectiveness of the leadership in the company studied here, represented by the ELD variable, we will start by analysing the primary items/variables which constitute it, i.e. its construct, so that we can assess the way in which questionnaire respondents perceive the characteristics of leadership, or, in other words, top management of the company under analysis. In order to assess and analyse the effectiveness of the company's leadership, the construct of the aggregate variable ELD comprises 17 significant primary variables / items, which express the characteristics of the company's leadership. The ELD variable has good internal coherence according to the value of its Cronbach's Alpha coefficient, which is 0.9647 (Table 1).

Table 1. Reliability analysis test scale

\begin{tabular}{|l|c|c|c|c|}
\hline \multicolumn{1}{|c|}{ Var } & Sign & $\begin{array}{c}\text { Number of items in the } \\
\text { scale }\end{array}$ & $\begin{array}{c}\text { Average interitem } \\
\text { covariance }\end{array}$ & Alpha \\
\hline TEAM & + & 6 & .2907387 & 0.8598 \\
\hline VAL & + & 10 & .1806469 & 0.8618 \\
\hline FACIL & + & 5 & .4180195 & 0.8909 \\
\hline ORT & + & 6 & .1997169 & 0.8582 \\
\hline ELD & + & 17 & .2484527 & 0.9647 \\
\hline
\end{tabular}

Source: Own determination

The main statistical indicators which characterise the $E L D$ variable are presented in table 2, which shows that the variable registers a good mean of 4.2970 and a standard deviation of 0.4964 . The standard error (0.0509) expresses a proximity between the value of the mean and its true value in relation to the total statistical population. At the same time, the coefficient of variation shows a good degree of homogeneity (0.1155) in the statistical population for which the variable was determined.

Tabel 2. Tabstat ELD

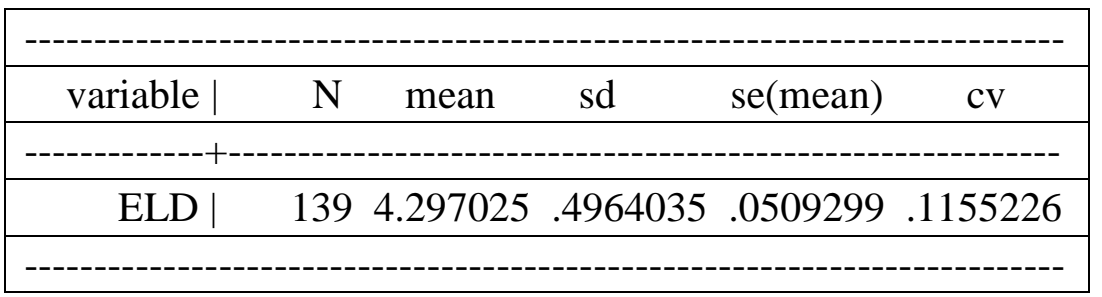

Source: Own determination

As concluded based on the analysis of the primary variables, the act of ensuring an effective leadership within the company which is the object of our study translates into adequate and effective behaviours with respect to:

- promoting a corporate culture based on vision and mission and on a common identity of the organisation's members, 4.324;

- $\quad$ strategic guidance of the company, 4.276; 
- promoting challenging values, directions of action and performance goals in an adequate and effective manner, 4.251;

- involvement in clearly elaborating and defining an adequate system of values which are shared with company employees, 4.279;

- orientation towards clients' needs and the market through a clear definition of the way to satisfy them and of the objectives regarding the improvement of company performance, 4.385;

- taking responsibility in relation to civil society and the community through active involvement in the external social environment, 4.228;

- promoting a vision of excellence through visible, firm and advised leadership, and effective, clear and substantial communication meant to channel employees' efforts towards the constant improvement of the organisation's performance, 4.2353;

- accessibility for lower hierarchic levels and maintaining permanent contact with employees, clients and suppliers, 4.209;

- supporting change in organisational culture with respect to performance when required, 4.194;

- exercising adequate and effective control over the process of making and implementing decisions within the company, 4.243;

- promoting a leadership style which facilitates the effective understanding and implementation of decisions, 4.235;

- effective involvement in promoting and sharing company values with team members, 4.201;

- consolidating trust among employees working either individually or as part of a team, 4.190;

- $\quad$ adequate and effective support and motivation for employees, 4.283;

- effective involvement in relationships with clients, partners and representatives of civil society, 4.307;

- the capacity to face the uncertainty generated by the increasingly dynamic environment in which the company operates, 4.281 ;

- $\quad$ promoting an ethical and sustainable business model, 4.258.

Moreover, the company's leadership is visible, firm and advised, and is greatly appreciated by questionnaire respondents, as is made clear by the high scores they assigned it (between 4.194 and 4.385). It is based on a vision of excellence and promotes challenging values, directions of action and performance goals within the company.

At the same time, top managers who team up with the company CEO also received high scores from the respondents thanks to their promoting certain adequate and effective types of behaviour with respect to:

- involvement in relationships with clients, partners and the community;

- a firm commitment to the process of continuous improvement;

- involvement in the elaboration, implementation and continuous improvement of best management practices within the company;

- motivating and supporting company employees to improve their individual and team performance;

- the capacity to face the uncertainty generated by an increasingly dynamic environment in which the company operates, etc.

These instances of appreciation, i.e. the registered scores, are due to respondents' perception of the contribution of the CEO and the top management team to the company's very high performance in the last 5 years, in terms of both financial and non-financial indicators. Furthermore, we can remark on the top management's expertise and experience, which have aided in creating and developing a 
functional organisational culture and in carrying out the necessary changes when required, thus enabling the employees to adapt more easily to an increasingly dynamic environment.

An important role in consolidating organisational culture in order to ensure leadership effectiveness belongs to the team leaders, who have the appropriate abilities to channel employees' attention and to communicate and share company values with them in a clear and adequate manner. Another important contribution with respect to promoting and sharing values within the company is that of executive managers, due to their personal involvement in the creation and implementation of an adequate and effective policy and in the promotion of ethics in all business processes.

\subsection{Analysis of organisational culture}

In the present study, organisational culture is based on Denison's model (Denison, 1990; Denison et. al., 2004; Denison et. al., 2012), taking the following features into consideration: orientation towards team work, sharing the company's core values, facilitating change and strategic orientation/direction. These elements are represented by the TEAM, VAL, FACIL, ORT variables, which, in terms of construction, have good internal coherence according to the values of their Cronbach's Alpha coefficients, namely: TEAM (0.8598); VAL (0.8618); FACIL (0.8909); ORT (0.8582) (table 1).

In order to analyse the features of organisational culture represented by the four variables in table 3 , we will use the indicators of descriptive statistics: mean, standard deviation, standard error and coefficient of variation.

Tabel 3. Tabstat TEAM VAL FACIL ORT

\begin{tabular}{|c|c|c|c|c|c|}
\hline variable | & $\mathrm{N}$ & mean & sd & se(mean) & CV \\
\hline \multicolumn{6}{|c|}{ 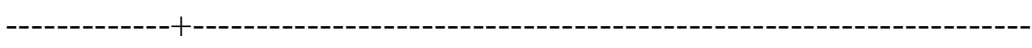 } \\
\hline TEAM & 137 & 4.133368 & .5469638 & .0561173 & 1323288 \\
\hline VAL | & 139 & 4.227895 & .4045852 & .0415096 & .0956942 \\
\hline FACIL | & 135 & 3.967469 & .5273785 & .0979317 & .1249508 \\
\hline ORT & 137 & 4.259838 & .4822803 & .0306868 & .1132156. \\
\hline
\end{tabular}

Source: Own determination

\section{Orientation towards team work}

Orientation towards team work as a feature of organisational culture highlights the fact that teams represent the company's main building block and measures the degree to which employees forming work teams at all organisational levels are involved in carrying out activities and processes in order to fulfil the company's goals and mission. It expresses the extent to which proactive cooperation, coordination and communication, together with the sharing of information, are encouraged in order to enable the development of employee potential, which is regarded as an important source of competitive edge for the company (Denison, 1990; Denison et. al., 2004; Denison et. al., 2012).

Orientation towards team work, represented by the TEAM variable, as an important feature of the culture of the company under analysis, comprises 6 significant primary variables (items), which show how respondents perceive the involvement of company members organised in teams in the attainment of its goals. It reveals the importance that company members assign to team work, which is considered the foundation of internal processes and of cooperation within the organisation. It has good internal coherence, with a Cronbach's Alpha coefficient of 0.8598 (table 1).

The main statistical indicators which characterise the TEAM variable register a good mean of 4.1333 and a standard deviation of 0.5469 . The standard error (0.0561) indicates a proximity between the value of the mean and its true value in relation to the total statistical population. At the 
same time, the coefficient of variation shows a good degree of homogeneity $(0.1323)$ in the statistical population for which the variable was determined (table 3).

The analysis of the primary variables (items) regarding orientation towards team work as perceived by questionnaire respondents, with their associated scores, highlights the following significant aspects:

- team cooperation/collaboration, beyond its functional roles, is actively encouraged within the company, 4.505;

- team work is the company's core characteristic (teams constitute the main building block of the organisation), 4.210;

- the manner of organising work within the company enables each employee to become aware of the relationship between his/her activity within the team and the goals of the organisation, 4.012;

- control within the company is mainly exercised horizontally and is founded on coordination in order to raise awareness of the fact that the manner of conducting one's work is more important than hierarchy, 3.831;

- company management provides a work environment which is conducive to effective team development, 3.989;

- company management is concerned with the development of teams based on proactive communication, 4.263.

The relatively lower score of the primary variable which refers to the manner in which control is exercised within the company, based on coordination, demands better awareness of the importance of finding the most adequate and effective methods of organising cooperation-based work in order to attain common goals.

The analysis of this variable shows that the company in this study is actively, effectively and efficiently involved in supporting work teams by providing the necessary resources and skills, and that it encourages proactive cooperation and communication in order to achieve strong team cohesion, which is an important factor in ensuring leadership effectiveness.

\section{Core values}

The core value system is fundamentally representative of the company under analysis, which consolidates coherence as a dimension of organisational culture. Core values determine the effectiveness of leadership and company performance by promoting adequate and effective attitudes and behaviours among the company's leaders and other members (London \& Mone, 2014; Hofstede and Hofstede 2005; Cameron and Quinn, 2006). At the same time, they ensure the consolidation of organisational culture, which fosters a sense of belonging to the organisation in its members.

The values in which company employees believe play a major part in the development and consolidation of organisational culture and in the improvement of leadership effectiveness, which are important for the enhancement of organisational performance.

Only an organisational culture which relies on a system of values shared by employees, as well as on their personal values, can actually contribute to the improvement of leadership effectiveness. Meanwhile, the changes required within organisational culture whenever they become necessary cannot be carried out without a strong system of values suited to the company's purposes and goals. Core values, represented by the VAL variable, constitute an important feature of the culture of the company under analysis. They comprise 10 significant primary variables (items) for ensuring organisational coherence as a measure of the degree to which they are shared by the members of the organisation. In terms of structure, the $V A L$ variable has good internal coherence, with a Cronbach's Alpha coefficient of 0.8618 (table 1).

The main statistical indicators which characterise this variable show that it has a good mean of 4.2278 and a standard deviation of 0.4045 . The standard error $(0.0415)$ indicates a proximity 
between the value of the mean and its true value in relation to the total statistical population. At the same time, the coefficient of variation shows a good degree of homogeneity (0.0956) in the statistical population for which the variable was determined (table 3).

The primary variables which make up the VAL variable, which are of significance for the company's system of values, with their associated scores, are based on the following aspects:

- there is a clear and coherent set of values within the company which regulate the manner in which business is conducted, 4.5473;

- the company has a code of ethics which adequately guides the behaviour of all employees, 4.4210;

- leadership is involved in clearly elaborating and defining an adequate system of values which is shared with the company's employees, 4.3789;

- the organisation's values, integrated into the management system, are adequately reflected in the company's public image, 4.2105;

- managers effectively share company values, impart confidence to subordinates and stimulate performance, 4.1921;

- company leadership is firmly committed to promoting high standards for improving and acknowledging performance, 4.1671;

- it correctly and transparently explains its expectations regarding subordinates' behaviours and attitudes, 4.1157;

- company managers are committed to personnel development and coaching in order to ensure a strong and diverse flow of talent, 4.1473;

- managers are committed to respecting the personal values of company members, 4.0421.

The effective implementation of values in the company under analysis is based on a rigorous planning process, which takes into consideration the assessment of the current situation by identifying the problems which should be the target of change. One critical aspect for the company is defining an adequate behaviour which must support the organisation's declared core values.

As indicated by the analysis of the scores of the primary variables represented by the $V A L$ variable based on the opinions of questionnaire respondents, we may conclude that the company has a clear and coherent set of values which ensure a strong organisational culture.

In this context, we may state that the key to the success of the company under analysis, aside from the quality of its products/services and the solutions offered to clients, is an organisational culture which ensures that all employees, from operators to company leaders, effectively know and share the organisation's core values and act in accordance with them, as shown by their behaviours and attitudes.

\section{Facilitation of change}

The facilitation of change as a feature of organisational culture refers to the sharing of new ideas out of a desire to try out new approaches in order to identify the necessity of change as part of business management, with the aim of developing the company's capacity to adapt to the execution of changes when required.

At the same time, it facilitates the analysis of the business environment in order to enable a swift reaction to internal and external organisational changes, which need to be conducted in anticipation of future changes (Denison, 2012; Kotter and Heskett, 1992).

The facilitation of change, represented by the FACIL variable, as a feature of organisational culture, consists structurally of 5 significant primary variables for ensuring company adaptability. The FACIL variable has good internal coherence, as proven by the reliability analysis, which gives a Cronbach's Alpha coefficient value of 0.8909 (table 1).

The main statistical indicators which characterise this variable show that it has a good mean of 3.9674 and a standard deviation of 0.5273 . The standard error (0.0979) indicates a good proximity 
between the value of the mean and its true value in relation to the total statistical population. At the same time, the coefficient of variation shows a good degree of homogeneity (0.1249) in the statistical population for which the variable was determined (table 3).

In the respondents' opinion, the most important aspects of change facilitation highlighted by the primary variables which make up the FACIL variable, with their associated scores, are the following:

- company managers are receptive to change, which they execute easily when required, 4.0375;

- the company is constantly concerned with adopting new adequate and effective ways of carrying out the work process, 4.1488;

- attempts at executing changes within the company are not met with resistance by employees, 3.7105;

- the company's various organisational structures cooperate effectively to carry out and implement change, 3.9052;

- the specific values of organisational culture, shared by company members, ensure the effectiveness of change strategies, 4.0375 .

The analysis of the FACIL variable, as perceived by questionnaire respondents, highlights the fact that the company in this study manages to promote adequate ways of executing changes within the organisation amongst its employees.

\section{Strategic orientation/direction}

Strategic orientation, represented by the $O R T$ variable, as a feature of organisational culture, provides a clear direction and strategic goals, which serve to define an adequate course of action for the organisation and its members (Denison, 2004; Hamel \& Prahalad, 1994).

As can be observed by analysing the opinions of questionnaire respondents, the aggregate variable ORT comprises 6 significant primary variables (items) which express a clear sense of direction to be followed within the company. It is a variable with good internal coherence, as proven by its Cronbach's Alpha coefficient of 0.8582.

The main statistical indicators which characterise this variable indicate a good mean of 4.2598 and a standard deviation of 0.4822 . The standard error (0.0306) indicates a good proximity between the value of the mean and its true value in relation to the total statistical population. At the same time, the coefficient of variation shows a good degree of homogeneity (0.1132) in the statistical population for which the variable was determined (table 3).

According to the questionnaire respondents, the primary variables which make up the ORT aggregate variable, with their associated scores, highlight the following aspects:

- the company has a well-defined long-term purpose and direction, 4.4372;

- the company strategy ensures the attainment of a competitive edge in an increasingly dynamic market, 4.3157;

- the company has a clear mission, which gives meaning and direction to the work of all employees, 4.2145;

- company management ensures the involvement of the main interested parties in the revision/modification of the action strategy and programmes, 4.1983;

- company behaviours and results are aligned with its strategic directions, 4.2024;

- company management ensures the transformation of strategies into adequate action plans/programmes/policies, 4.1902.

All these aspects confirm the fact that company leaders set clear, realistic and ambitious goals and ensure a broad consensus regarding the organisation's goals. At the same time, the company under analysis has a well-defined long-term direction, while its results are in line with the organisation's strategies, which gives the mission a clear meaning and its members a strong sense of confidence in its goals and strategies. 


\subsection{The impact of organisational culture on leadership effectiveness}

Starting from the importance of ensuring leadership effectiveness within the company under analysis, we have set out to determine the impact of organisational culture on leadership, in order to develop a performance improvement programme founded on both theory and best practices in the field of management. To that purpose, we studied the extent of the impact which the independent variables TEAM, VAL, FACIL, ORT, as features of organisational culture, have on the dependent variable $E L D$, which summarises leadership effectiveness, by using simple linear regression analysis (table 4).

Table 4. The impact of independent variables TEAM, VAL, FACIL, ORT on the dependent variable $E L D$

\begin{tabular}{|l|c|l|l|l|l|l|}
\hline $\begin{array}{l}\text { Independent } \\
\text { variable }\end{array}$ & $\mathbf{N}$ & $\begin{array}{c}\text { Prob }> \\
\mathbf{F}\end{array}$ & $\begin{array}{c}\text { R- } \\
\text { squared }\end{array}$ & Coef. & $\mathbf{t}$ & $\mathbf{P}>|\mathbf{t}|$ \\
\hline TEAM & 137 & 0.0000 & 0.8423 & .8329319 & 17.54 & 0.000 \\
\hline VAL & 139 & 0.0000 & 0.7126 & .8858837 & 18.10 & 0.000 \\
\hline FACIL & 135 & 0.0000 & 0.6073 & .6928336 & 10.03 & 0.000 \\
\hline ORT & 137 & 0.0000 & 0.8121 & .8254094 & 15.81 & 0.000 \\
\hline \multicolumn{7}{|c|}{ Source: Own determination } \\
\hline
\end{tabular}

Based on the results of the regression analysis, summarised in table 4, we can, from a statistical point of view, draw the following conclusions on the independent variables:

- TEAM has a significant and positive impact on the dependent variable $E L D$, which expresses leadership effectiveness. To support this statement, there is the ' $F$ ' test, with its Prob $>F=$ 0.0000 . The $R$-squared value (0.8423) shows that the variation of the independent variable TEAM explains $84.23 \%$ of the variation of the dependent variable ELD. As the value of $t$ is significantly different from zero, and $\mathrm{P}>|\mathrm{t}|$ is lower than 0.05 , the regression coefficient indicates that the independent variable TEAM has a significant impact on the dependent variable $E L D$, as for an increase of the independent variable TEAM by one unit, the dependent variable ELD increases by 0.8329 units;

- $V A L$ has a significant and positive impact on the dependent variable $E L D$, which expresses leadership effectiveness. To support this statement, there is the ' $F$ ' test, with its Prob $>F=$ 0.0000 . The $R$-squared value $(0.7126)$ shows that the variation of the independent variable $V A L$ explains $71.26 \%$ of the variation of the dependent variable ELD. As the value of $t$ is significantly different from zero, and $\mathrm{P}>|\mathrm{t}|$ is lower than 0.05 , the regression coefficient indicates that the independent variable $V A L$ has a significant impact on the dependent variable $E L D$, as for an increase of the independent variable $V A L$ by one unit, the dependent variable $E L D$ increases by 0.8858 units;

- FACIL has a significant and positive impact on the dependent variable ELD, which expresses leadership effectiveness. To support this statement, there is the ' $F$ ' test, with its Prob $>\mathrm{F}=0.0000$. The $R$-squared value (0.6073) shows that the variation of the independent variable FACIL explains $60.73 \%$ of the variation of the dependent variable ELD. As the value of $t$ is significantly different from zero, and $\mathrm{P}>|\mathrm{t}|$ is lower than 0.05 , the regression coefficient indicates that the independent variable FACIL has a significant impact on the dependent variable $E L D$, as for an increase of the independent variable FACIL by one unit, the dependent variable $E L D$ rises by 0.6928 units;

- $\quad$ ORT has a significant and positive impact on the dependent variable $E L D$, which expresses leadership effectiveness. To support this statement, there is the ' $F$ ' test, with its Prob $>F=$ 0.0000 . The $R$-squared value (0.8121) shows that the variation of the independent variable ORT explains $81.21 \%$ of the variation of the dependent variable ELD. As the value of $t$ is 
significantly different from zero, and $\mathrm{P}>|\mathrm{t}|$ is lower than 0.05 , the regression coefficient indicates that the independent variable ORT has a significant impact on the dependent variable $E L D$, as for an increase of the independent variable $O R T$ by one unit, the dependent variable $E L D$ rises by 0.8254 units.

These results validate the chosen analysis model, in that the analysis of the regression between the variables studied using this model is adequate.

The results summarised in table 4 show that all the features of organisational culture have a significant and positive impact on leadership effectiveness. We notice that the independent variables TEAM and ORT explain the variation of the dependent variable ELD to the greatest extent. The reason behind this is that company leaders are firmly committed to supporting teams and share a system of core values which ensure adequate motivation in attaining organisational objectives with the other employees. At the same time, company leaders provide a clear direction and set realistic and ambitious strategic goals, which serve to define an adequate and effective course of action for the members of the organisation.

Consequently, the aim formulated as part of the current research, namely the analysis of the impact of organisational culture on leadership effectiveness, highlights the fact that it is validated, which leads to the conclusion that team work, core values, facilitation of change and strategic orientation are good predictors of the improvement of leadership effectiveness within the company under analysis.

\section{CONCLUSIONS}

As concluded based on the analysed data, organisational culture is analysed by means of the four features which, in turn, influence the effectiveness of company leadership to the greatest extent by exercising influence and shaping the behaviour of company members.

Given the importance of ensuring effective leadership, leaders must be aware of their considerable role in the growth and development of the company and realise that its strategic direction and the support given to the continuous improvement of its processes and activities are mainly their responsibility and that of all the other company members, which is why they need to promote a strong organisational culture.

Leadership is considered a key factor in ensuring the competitiveness of an organisation and its reputation in the external environment in comparison to its competitors (Blanchard, 2009; Conger, 1989).

For the success of a company to be ensured by the significant and strong positive connection between the features of organisational culture included in this study and the effectiveness of leadership, its leaders must be flexible and capable of finding creative and efficient solutions, understand the various cultures/microcultures, provide individual and team motivation, have decision-making skills, possess adequate levels of creativity, and be able to effectively manage change, effective communication and personal ethics. Leadership must have a proactive futureoriented approach, which is why it needs to secure the appropriate skills to build teams successfully, provide a clear direction and carry out necessary changes in order to attain company goals.

Improving and capitalising on the relationship between the features of organisational culture and company leadership in order to ensure its success require taking into consideration the following aspects:

- the balancing, coordination and synergy of leadership and team work through a deep understanding of human behaviour and motivation;

- making sure leaders and team members seek out adequate tools to promote a set of behaviours which should ensure cooperation, motivation, fairness, quality, responsibility and balance, in order to consolidate a strong and adequate culture able to express the company's vision in accordance with the demands of interested parties; 
- organising adequate and effective training sessions to enable the leader to understand the team's culture/microculture and find ways to ensure the success of every team and each of its members;

- providing a clear strategic direction which should ensure the alignment of the work team's goals with those of the organisation, in accordance with company strategies.

\section{REFERENCES}

Al-Tit, A., A. (2017). Factors affecting the organizational performance of manufacturing firms. International Journal of Engineering Business Management, 9, 1-9.

Ashkanasy, N., M. \& Dorris, A., B. (2018). Organizational culture and climate. In Anderson N., Ones D., S., Sinangil H., K. \& Viswesvaran C. (Eds.), The Sage Handbook of Industrial, Work \& Organizational Psychology. (pp.187-205). Thousand Oaks, CA, United States: Sage Publishing.

Bass, B., M. \& Avolio, B., J. (1993). Transformational leadership and organizational culture. Public Administration Quarterly,17(1), 112-121.

Blanchard, K. (2009). Leading at a Higher Level, Revised and Expanded Edition: Blanchard on Leadership and Creating High Performing Organizations. New Jersey, NJ: Pearson Prentice Hall Press,

Cameron, K., S. \& Quinn, R., E. (2006). Diagnosing and changing organizational culture. San Francisco, CA: Jossey-Bass.

Conger, J., A. (1989). Leadership: The art of empowering others. The Academy of Management Executive, 3(1), 17-24.

Denison, D., R. (1990). Corporate Culture and Organisational Effectiveness. New York, NY: Wiley.

Denison, D., R., Haaland, S. \& Goelzer, P. (2004). Corporate Culture and Organizational Effectiveness: Is Asia Different From the Rest of the World? Elsevier, Inc .Organizational Dynamics, 33(1), 98-109.

Denison, D., R., Hooijberg, R., Lane, N. \& Lief, C. (2012). Change in Global Organizations: Aligning Culture and Strategy. San Francisco, CA: Jossey Bass.

Hamel, G. \& Prahalad, C., K. (1994). Competing for the Future. Retrieved August 20,2020, from https://hbr.org/1994/07/competing-for-the-future.

Hofstede, G. \& Hofstede, G., J. (2005). Cultures and organizations: Software of the mind. New York: McGraw-Hill.

Howell, J., M. \& Avolio, B., J. (1993). Transformational leadership, transactional leadership, locus of control, and support for innovation: Key predictors of consolidated-business-unit performance. Journal of Applied Psychology, 78(6), 891-902.

Kotter, J., P. \& Heskett, J., L. (1992). Corporate Culture and Performance. New York: The Free Press.

London, M. \& Mone, E., M. (2014). Performance management: Processes that reflect and shape organizational culture and climate. In K. M. Barbera (Ed.), The Oxford Handbook of Organizational Climate and Culture. Oxford, England: Oxford University Press.

O’Reilly III, C., A., Caldwell, D., F., Chatman, J., A. \& Doerr, B. (2014). The promise and problems of organizational culture: CEO personality, culture, and firm performance. Group \& Organization Management, 39(6), 595-625.

Ogbonna, E. \& Harris, L. (2000). Leadership style, organizational culture and performance: Empirical evidence from UK companies. International Journal of Human Resources Management, 11(4), 766-788.

Parry, K., W. \& Proctor-Thomson, S., B. (2002). Leadership, culture and performance: The case of the New Zealand public sector. Journal of Change Management, 3(4), 376-399. 
Quinn, R., E. \& Rohrbaugh, J. (1983). A spatial model of effectiveness criteria: Towards a competing values approach to organizational analysis. Management Science, 29(3), 363-377.

Schein, E., H. (1992). Organizational Culture and Leadership. $2^{\text {nd }}$ edition. San Francisco, CA: Jossey-Bass.

Schein, E., H. (2009). The Corporate Culture Survival Guide. 4-th edition, New and Revised Edition, San Francisco, CA: Jossey-Bass.

Schein, E., H. (2010). Organizational culture and leadership. $4^{\text {th }}$ edition. San Francisco, CA: Jossey-Bass.

Schein, E. H. (2017). Organizational culture and leadership. $5^{\text {th }}$ edition, New Jersey, NJ: John Wiley \& Sons, Inc.

Schneider, B., Ehrhart, M., G. \& Macey, W., H. (2013). Organizational climate and culture. Annual Review of Psychology, 64, 361-388.

Tsui, A., S., Zhang, Z., Wang, H., Xin, K., R. \& Wu, J., B. (2006). Unpacking the relationship between CEO leadership behavior and organizational culture. Leadership Quarterly, 17, 113137.

Wilderom, C., P. \& van den Berg, P., T. (2000). Firm culture and leadership as firm performance predictors: A resource-based perspective. New York, NY: Tilburg University. 